\title{
«PemIK (PemK/Peml) type II TA system from Klebsiella pneumoniae clinical strains inhibits lytic phage»
}

\section{Ines Bleriot}

Hospital A Coruña (CHUAC), University of A Coruña (UDC), A Coruña

\section{Lucia Blasco}

Hospital A Coruña (CHUAC), University of A Coruña (UDC), A Coruña

\section{Olga Pacios}

Hospital A Coruña (CHUAC), University of A Coruña (UDC), A Coruña

\section{Laura Fernández-García}

Hospital A Coruña (CHUAC), University of A Coruña (UDC), A Coruña

\section{Antón Ambroa}

Hospital A Coruña (CHUAC), University of A Coruña (UDC), A Coruña

\section{María López}

Hospital A Coruña (CHUAC), University of A Coruña (UDC), A Coruña

\section{Concha Ortiz-Cartagena}

Hospital A Coruña (CHUAC), University of A Coruña (UDC), A Coruña

\section{Felipe Fernández Cuenca}

Hospital Universitario Virgen Macarena, University of Seville, Biomedicine Institute of Seville (IBIS)

\section{Jesús Oteo}

Institute of Health Carlos III

\section{Álvaro Pascual}

Hospital Universitario Virgen Macarena, University of Seville, Biomedicine Institute of Seville (IBIS)

\section{Luis Martínez-Martínez}

UGC Microbiología, Hospital Reina Sofía, Universidad de Córdoba, Instituto Maimónides de Investigación Biomédica de Córdoba (IMIBIC)

\section{Pilar Domingo-Calap}

Universitat de València, Universitat de València-CSIC

\section{Thomas K. Wood}

Pennsylvania State University

\section{Maria Tomás ( MA.del.Mar.Tomas.Carmona@sergas.es ) \\ Hospital A Coruña (CHUAC), University of A Coruña (UDC), A Coruña}


Keywords: Klebsiella pneumoniae, toxin-antitoxin system, PemK/Peml TA system, phage inhibition

Posted Date: July 12th, 2021

DOI: https://doi.org/10.21203/rs.3.rs-679460/v1

License: (c) (1) This work is licensed under a Creative Commons Attribution 4.0 International License. Read Full License 


\section{Abstract}

Since their discovery, toxin-antitoxin systems have captivated many scientists. Recent studies demonstrated that a key role of TA systems is phage inhibition. Therefore, the aim of this study was to investigate the role of the PemIK (PemK/Peml) type II TA system in phage inhibition by its intrinsic expression in clinical strains of Klebsiella pneumoniae carrying OXA-48 carbapenemase and by induced its expression in an IPTG-inducible plasmid in a reference strain of $K$. pneumoniae ATCC $® 10031^{\mathrm{TM}}$. qRTPCR revealed that pemK toxin in clinical strain ST16-OXA48 was induced when phage did not infect the strain, whereas when phage infection was successful pemK toxin was not induced. In addition, induced expression of the whole system did not inhibit phage infection, whereas overexpression of the pemK toxin prevented infection during the first hours. To investigate the molecular mechanism involved in the PemK toxin-mediated inhibition of phage infection, an assay measuring metabolic activity was performed, which revealed that production of toxin PemK led to the dormancy of the bacteria. Thus, we demonstrate that the PemK/Peml TA system plays a role in phage infection, and that the action of the free toxin causes the cells to go into a dormant state resulting in inhibition of phage infections.

\section{Introduction}

Bacteriophages, also known as "phages", are viruses that infect bacteria. These prokaryotic viruses are considered the most abundant biological entities on Earth with $10^{31}$ viral particles, found in all environmental niches colonized by bacteria ${ }^{1,2}$. Traditionally, phages have been divided based on their life cycle into either lytic or lysogenic phages. Most lytic phages, after infecting their host, use the bacterial machinery to replicate, transcribe, and/or translate their nucleic acid to finally lyse the bacterial cell, releasing many viral particles, while lysogenic phages can integrate their genome into the bacterial chromosome or follow the lytic cycle, being known as prophages or temperate phages ${ }^{3}$. Temperate phages are believed to be responsible for introducing a large number of genes that provide different functions to their bacterial hosts. Accordingly, the phage packaging system can act as mobile elements for horizontal gene transfer, even modulating the behavior of these bacteria, through virulence and defense genes ${ }^{1}$. The continuous war between phages and bacteria has led to the coevolution of both entities, so bacteria developed defenses to protect themselves from the phages while the phages in turn developed counterstrategies to evade those defenses ${ }^{4}$. Examples of defense mechanisms against the continuous attacks of phages are: (i) surface alterations to avoid phage adsorption, (ii) prevention of phage DNA injection, (iii) restriction of incoming DNA, (iv) acquiring phage-specific immunity through clustered regularly interspaced short palindromic repeats (CRISPR) and (v) toxin-antitoxin (TA) systems ${ }^{5}$.

TA systems are widely distributed in bacterial strains ${ }^{6}$, located on bacterial chromosomes, plasmids, and in phages ${ }^{7}$. The wide range of TA systems have been classified into eight groups (type I-VIII) based on the nature and mechanism of action of the antitoxin ${ }^{8}$. These systems are encoded by adjacent genes, generally consisting of two components: a stable toxin, and an unstable antitoxin, which is degraded under stress conditions by protease systems ${ }^{9}$, leading to toxin activation, often resulting in reduced 
bacterial metabolism ${ }^{8}$. The most prevalent kind of TA systems is the type II TA system, where both toxin and antitoxin are proteins ${ }^{10}$, encoded in the same operon and co-expressed ${ }^{11}$, and where the antitoxin neutralizes the toxicity of the toxin by direct protein-protein interactions. Toxin targets vary, but most inhibit a central cellular process, such as translation or DNA replication ${ }^{12}$. Since their discovery in a plasmid in 1983 by Ogura and Sota ${ }^{13}$, TA systems have captivated the minds of many scientists, who have attributed to them multiple functions in cell physiology such as plasmid maintenance ${ }^{13,14}$ which play a crucial role in the dissemination and evolution of antibiotic resistance, such as maintaining multiresistant plasmids ${ }^{7,15}$, bacterial persistence ${ }^{16-19}$, biofilm formation ${ }^{20,21}$, general stress response ${ }^{22}$, and phage inhibition ${ }^{5,23-26}$. However, today there are still many unanswered questions in regard to their functions in cell physiology. Recently, we proposed that the main physiological role of TA systems is the inhibition of phages ${ }^{8}$.

However, the relevance of TA systems to phage inhibition has been described by relatively few reports. The first involvement was demonstrated by the type I TA system Hok/SoK from the R1 plasmid, which inhibited T4 phage infection, most likely due to activation of the toxin after global transcription reduction by the lytic phage ${ }^{23}$. Additional evidence of the role of TA systems was provided years later, when the type II TA systems MazF/MazE and RnIA/RnlB showed inhibition of infection by phage P1 and T4, respectively $24,25,27$. More recently the discovery of the type III TA systems ToxN/Toxl, from plasmid pECA1039 of Erwinia carotovora, revealed inhibition of phages phiA2 and phiM1 ${ }^{5}$. Finally, the well-known abortive infection AbiEii/AbiEi system, from plasmid pNP40, that inhibits the 936 phages family, was suggested to be a type IV TA system ${ }^{26}$.

Based on the findings, the aim of this work was to study the role of the type II TA system PemIK (PemK/Peml) harboring by a plasmid, previously isolated and characterized by our group ${ }^{28}$, by intrinsic expression of this system in clinical strains of Klebsiella pneumoniae carrying the OXA-48 carbapenemase and by induced expression of this system in an IPTG-inducible expression plasmid in a reference strain of $K$. pneumoniae ATCC $® 10031^{\text {TM }}$.

\section{Results}

\section{Isolation, propagation and electron microscopy of phages}

The ten phages used in this study, named according to the accepted practices ${ }^{29}$ (Fig. 1), were obtained from residual water samples, using as host the reference strain of $K$. pneumoniae ATCC $® 10031^{\mathrm{TM}}$. Focusing on the morphology of the plaques produced by the different phages, we observed that the size of the plaques oscillated from 2.5 to $7.8 \mathrm{~mm}$ in diameter on the lawn of ATCC® $10031^{\text {TM }}$ cells (Fig. 1). In addition, all of them were surrounded by a halo that is often interpreted as an indicator of depolymerasemediated digestion of bacterial capsules ${ }^{30}$. Transmission electron microscopy images revealed that all the phages belonged to the order Caudovirales, i.e. tailed phages of double-stranded DNA (dsDNA). All of them present an icosahedral head, however most had a long and flexible tail characteristic to the 
Siphoviridae family, while one phage, vB_KpnP-VAC1, presented a small tail, characteristic to the Podoviridae family (Fig. 1).

\section{Phage genome sequencing}

Genome sequencing revealed that all phages under study, available in Genbank BioProject PRJNA739095 (http://www.ncbi.nlm.nih.gov/bioproject/739095)(Table 1), were lytic Caudovirales phages, lacking lysogenic genes such as integrases, recombinase, repressor and excisionase. In addition, sequencing corroborated the TEM results by confirming that phage vB_KpnP-VAC1 was a member of the Podoviridae family, while the other nine phages were members of the Siphoviridae family. Furthermore, it allowed them to be classified by genus by sequence homology with the other sequences available in the NCBI database, which revealed that phage VB_KpnP-VAC1 was a member of the genus Teetrevirus, while the other phages were members of the genus Webervirus. Phage size ranged from 39,498 to $53,113 \mathrm{bp}$, and guanine-cytosine content ranged from $47.86 \%$ to $51.63 \%$ (Table 1). Sequence analysis revealed that the proteins were organized into functional modules within the genome, grouping them into genes related to structure, packaging, lysis, transcription and regulation. Focusing on the lysis genes, all phages had endolysins and holin, two proteins responsible of the degradation of the bacterial cell wall during the infection of the host; however, a difference was observed in terms of spanin (protein involved in the lysis process in gram-negative host) depending on the family to which the phage belonged, i.e. the Siphoviridae phages had a unimolecular spanin (U-Spanin) while the Podoviridae phage had an heterodimer molecule spanin (I-Spanin). Finally, regarding host capsid degradation genes during virus entry, five of the phages were found to have depolymerase (vB_KpnS-VAC2, vB_KpnS-VAC4, vB_KpnSVAC5, vB_KpnS-VAC6 and vB_KpnS-VAC10), and three of them (vB_KpnS-VAC2, vB_KpnS-VAC4 and vB_KpnS-VAC6) had two different depolymerases. 
Table 1

Characteristics of the genome sequences of the ten lytic phages under study (BioProject accession number: PRJNA739095; http://www.ncbi.nlm.nih.gov/bioproject/739095).

\begin{tabular}{|llllll|}
\hline Phages & Accession no. & Family & Genus & Genome size (bp) & G + C (\%) \\
\hline vB_KpnP-VAC1 & SAMN19773206 & Podoviridae & Teetrevirus & 39.498 & 50.75 \\
\hline vB_KpnS-VAC2 & SAMN19773207 & Siphoviridae & Webervirus & 51.911 & 47.86 \\
\hline vB_KpnS-VAC4 & SAMN19773215 & Siphoviridae & Webervirus & 45.685 & 51.11 \\
\hline vB_KpnS-VAC5 & SAMN19773216 & Siphoviridae & Webervirus & 49.763 & 50.46 \\
\hline vB_KpnS-VAC6 & SAMN19773219 & Siphoviridae & Webervirus & 51.681 & 51.63 \\
\hline vB_KpnS-VAC7 & SAMN19773220 & Siphoviridae & Webervirus & 49.811 & 51.25 \\
\hline vB_KpnS-VAC8 & SAMN19773224 & Siphoviridae & Webervirus & 49.046 & 50.52 \\
\hline vB_KpnS-VAC9 & SAMN19773231 & Siphoviridae & Webervirus & 53.113 & 50.52 \\
\hline vB_KpnS-VAC10 & SAMN19773232 & Siphoviridae & Webervirus & 49.062 & 50.65 \\
\hline vB_KpnS-VAC11 & SAMN19773540 & Siphoviridae & Webervirus & 48.953 & 50.83 \\
\hline Phage infeCtivity aSSays in Solid & medium & \\
\hline
\end{tabular}

The phages infectivity assay in solid medium was performed using the spot test technique on the collection of clinical strains of K. pneumoniae to see the susceptibility of the strains to phages (Fig. 2A). All strains in the collection harbor carbapenemase OXA-48 and the PemK/PemI TA system, and present different capsular types. The results obtained showed that the clinical strain ST16-OXA48 was the most susceptible strain to phages, as it was infected by 10 different phages. In contrast, the clinical strains ST405-OXA48 and ST15-OXA48 ${ }^{\mathrm{C}}$ were not infected by any of the phages assayed. Based on these results, we selected the susceptible clinical strain ST16-OXA48 and two lytic phages according to their infectivity capacity: vB_KpnP-VAC1 with no infectivity and vB_KpnS-VAC7 with high infectivity (Fig. 2B), for the remaining experiments.

\section{Phage adsorption and One-Step growth curve}

The adsorption assay was performed to study the adsorption of the phage to the bacterial surface receptors with the strain and phages previously selected. Phage vB_KpnP-VAC1 showed a slight adsorption with $27.08 \%$ of phage adsorbed at 10 min on strain ST16-OXA48. While phage vB_KpnSVAC7 showed high percentage of adsorption with $88.69 \%$ phage adsorbed at 6 minutes (Fig. 2C). Accordingly, a one-step growth curve was performed with phage vB_KpnS-VAC7 to determine the latency time and burst size, which were respectively $6 \mathrm{~min}$ and $15 \pm 2$ PFU (Fig. 2D). In the case of phage vB_KpnP-VAC1, the one-step growth curve was not performed because the phage was not able to produce a successful infection of the strain. 
Relative expression of the PemK/Peml TA system in presence of phages: vB_KpnP-VAC1 and vB_KpnSVAC7 phages by qRT-PCR.

The relative expression of the pemK toxin gene with respect to the pem/ antitoxin gene in the clinical strain ST16-OXA48 after 15 min of phage infection was significantly different according to the phage used for infection (Fig. 2E). Indeed, in the case of inhibited infection for the phage vB_KpnP-VAC1, the pemK toxin was found to be over-expressed (1.5-fold) with respect to the antitoxin. Whereas, in the case of infection with phage vB_KpnS-VAC7, the toxin was not found to be over-expressed relative to the antitoxin (0.7-fold). Both patterns are significantly different from the expression of this system in the absence of infection (control).

\section{Induced expression of TA system}

The ability of the PemK/Peml TA system to inhibit phage during induced expression of both genes was tested by monitoring infection with the 10 lytic phages at an $\mathrm{MOI}$ of 0.1 in the transformed strains: ATCC $\circledast 10031^{\mathrm{TM}} / \mathrm{pCA} 24 \mathrm{~N}$, ATCC $\circledast 10031^{\mathrm{TM}} / \mathrm{pCA} 24 \mathrm{~N}$ (pemK/peml) and ATCC $\left(10031^{\mathrm{TM}} / \mathrm{pCA} 24 \mathrm{~N}\right.$ (pemK) (Fig. 3). As shown in all the curves, overexpression of the whole pemK/pem/TA locus did not inhibit any of the phages, with no significant difference with the strain with the empty-plasmid. However, overexpression of the pemK toxin alone inhibited infection by all 10 phages during the first hours. These results were corroborated by the significantly lower $\mathrm{PFU} / \mathrm{mL}$ values after $1 \mathrm{~h}$ post-infection for strain ATCC $\circledast 10031^{\mathrm{TM}} / \mathrm{pCA} 24 \mathrm{~N}$ (pemK) compared to the strains ATCC $\otimes 10031^{\mathrm{TM}} / \mathrm{pCA} 24 \mathrm{~N}$ and ATCC ${ }^{8} 10031^{\mathrm{TM}} / \mathrm{pCA} 24 \mathrm{~N}$ (pemK/peml) (Fig. 3). Furthermore, a significant increase in PFU/mL of the ATCC $\circledast 10031 \mathrm{TM} / \mathrm{pCA} 24 \mathrm{~N}$ (pemK) strain was observed at $3 \mathrm{~h}$ post-infection, which corresponds with the observed decrease in $\mathrm{OD}_{600 \mathrm{~nm}}$, and thus with the infection of the strain by the phages, traducing a reversible effect of the toxin in the arrest of the viral life cycle.

In order to rule out that the effect observed in the different infection curves was due solely to IPTG induction of toxin gene pemK, control of induction without infection was performed (Fig. 4A and B). As a result, the overexpression of pemK in the strain ATCC $® 10031^{\mathrm{TM}} / \mathrm{pCA} 24 \mathrm{~N}$ (pemK) inhibited bacterial growth during the first three hours until the strain regrew to double the $\mathrm{OD}_{600 \mathrm{~nm}}$ at $6 \mathrm{~h}$ after induction, while the overexpression of the whole pemK/pem/TA system in the strain ATCC $810031^{\mathrm{TM}} / \mathrm{pCA} 24 \mathrm{~N}$ (pemK/pemI) led to normal growth, with no significant differences with the strain ATCC $\circledast 10031^{\mathrm{TM}} / \mathrm{pCA} 24 \mathrm{~N}$ (Fig. 4C).

\section{Enzymatic assay using the cell proliferation reagent WST-1}

The assay, which measures the ubiquitous reducing agents NADH and NADPH as biochemical markers to assess the metabolic activity of the cell, revealed that the transformed strains ATCC $810031^{\mathrm{TM}} / \mathrm{pCA} 24 \mathrm{~N}$ as well as ATCC ${ }^{8} 10031^{\mathrm{TM}} / \mathrm{pCA} 24 \mathrm{~N}$ (pemK/peml) without phage infection showed a metabolic activity reaching a $\mathrm{OD}_{480 \mathrm{~nm}}=0.337$ and 0.178 , respectively, after $2 \mathrm{~h}$ of induction with IPTG (Fig. 4D). In contrast, as expected, the strains ATCC $\AA 10031^{\mathrm{TM}} / \mathrm{pCA} 24 \mathrm{~N}$ and $\mathrm{ATCC}{ }^{\circledR} 10031^{\mathrm{TM}} / \mathrm{pCA} 24 \mathrm{~N}$ (pemK/peml) infected by 
the phage vB_KpnP-VAC1 lacked metabolic activity $\left(\mathrm{OD}_{480 \mathrm{~nm}}<0.1\right)$, indicating cell death due to phage infection. However, for strain ATCC $\AA 10031^{\mathrm{TM}} / \mathrm{pCA} 24 \mathrm{~N}$ (pemK), we observed that the strain lacked metabolic activity both with and without phage infection $\left(\mathrm{OD}_{480 \mathrm{~nm}}<0.1\right)$. This data indicates that overexpression of the toxin leads to a dormant state of the cell, which prevents phage infection.

\section{Discussion}

Recent studies have revealed that the key role of TA systems in bacterial cell physiology could be related to phage inhibition. In this regard, here we demonstrate the involvement of the type II TA system PemK/Peml in the reversible inhibition of phage infection caused by cell dormancy due to the effect of the free toxin.

First, focusing on the phages studied, TEM and sequencing revealed that they were all lytic phages belonging to the order Caudovirales, i.e. dsDNA-tailed bacteriophages, most of them being members of the genus Webervirus belonging to the family Siphoviridae and one member of the genus Teetrevirus belonging to the family Podoviridae.

Regarding the intrinsic study, the phage infectivity assay in solid medium revealed that a high percentage of strains were either not infected by the phages $(66 \%)$ or were only weakly infected $(15 \%)$. Therefore, given that all clinical strains studied harbor the PemK/PemI TA system, we reasoned this type II TA system could be probably involved in the inhibition of phage infection. For this purpose, the intrinsic study focused on two lytic phages that, despite being able to bind to the bacterial surface receptors of clinical strain ST16-OXA48, showed different patterns of infectivity in the solid medium infectivity assay: phage vB_KpnP-VAC1, which did not show successful infection, and phage vB_KpnS-VAC7, which showed successful infection. Notably, similar phenomena where adsorption to bacterial surface receptors does not explicitly imply successful infection have already been described in the literature ${ }^{31}$. Next, to study more specifically the role of the PemK/Peml system in phage infection, the relative expression of the pemK toxin with respect to the pem/antitoxin was studied by qRT-PCR in the clinical strain ST16-OXA48. Relative expression revealed two significantly different expression patterns depending on whether the strain was successfully infected by the phage (vB_KpnS-VAC7) or not (vB_KpnP-VAC1). Thus, overexpression of the toxin, in the case of the phage vB_KpnP-VAC1, allowed the bacterium to protect themselves from phage infection by the action of the free toxin that inhibited phage infection. Furthermore, the recent study of Wicke et al. (2020), demonstrated the reverse effect, i.e. enrichment of ParD antitoxin transcripts of the ParE/ParD type II TA system, leads to successful infection of the strain by the phage, as the viral DNA is protected from the deleterious action of the ParE toxin ${ }^{32}$. Besides, it has been described that phage often harbor specific protease inhibitors that can interfere with the degradation of antitoxins ${ }^{33}$. Thus, the host antitoxin maintains a complex with the host toxin allowing phage infection to proceed.

To better understand the role of the PemK toxin in phage inhibition, we performed an induced expression study of the TA system using an IPTG-induced expression plasmid. The study revealed that 
overexpression of the pemK toxin led to inhibition of phage infection during the first hours. In contrast, overexpression of the complete pemK/pem/TA system, with the PemK toxin blocked by the antitoxin Peml, did not confer any protection against phage infection (similar to the empty plasmid control). It is widely described that toxins of type II TA systems lead to down-regulation of cell metabolism as gene transcription is inhibited ${ }^{19,28}$. In this case the metabolic measurement by the enzymatic assay with the WST-1 reagent revealed that overexpression of pemK toxin led to the dormancy of bacterial cells after $2 \mathrm{~h}$ of induction with IPTG. However, bacteriophages are viruses that require the machinery of their bacterial hosts to replicate ${ }^{34}$. Therefore, as the cell is in a dormant state, the bacteriophage cannot replicate and is therefore unable to proliferate. This was observed by enumerating the PFU/mL of the ATCC ${ }^{8} 10031^{\mathrm{TM}} / \mathrm{pCA} 24 \mathrm{~N}$ (pemK) strain, where the phage counts were significantly lower than in the strains ATCC $\AA 10031^{\mathrm{TM}} / \mathrm{pCA} 24 \mathrm{~N}$ and ATCC $\AA 10031^{\mathrm{TM}} / \mathrm{pCA} 24 \mathrm{~N}$ (pemK/peml). These results confirm that the presence of free toxin ${ }^{33,35}$, protects the bacteria against phage infection during the first hours, through dormancy of the bacterial cells. However, in all infection curves of the ATCC $810031^{\mathrm{TM}} / \mathrm{pCA} 24 \mathrm{~N}$ (pemK) strain, we observed a reversible effect of viral cycle arrest, similar to that presented in the study of Moreno del-Aramo et al. $2020^{36}$. Indeed, after $3 \mathrm{~h}$ post-infection the phages were able to infect the strain, resulting in a decrease in $\mathrm{OD}_{600 \mathrm{~nm}}$ (opposite effect to that observed in the presence of IPTG induction and absence of phage infection) and an increase in phage (PFU/mL). This could be explained by a possible autoregulation of the toxin through its own endoribonuclease activity ${ }^{37,38}$ as was previously described in the homologous system MazF/MazE type II TA system in which, in the presence of stress, MazF toxin cleaves its own mRNA, thus autoregulating its expression ${ }^{39}$. Therefore, the bacterium returns to a metabolically active stage, allowing infection by the remaining phages present in the medium.

\section{Conclusion}

This is the first study about the role of the plasmidic type II TA system PemK/Peml in the phage inhibition. The results obtained throughout this study demonstrate that the dormancy of bacterial cells due to the action of pemK toxin leads to inhibition of phage infection. This captivating field is in its infancy; hence, it requires further analyses to improve the understanding of the relationship between TA systems and phage infection.

\section{Material And Methods}

\section{Bacterial strains and plasmid}

A collection of clinical strains of $K$. pneumoniae, harboring the OXA-48 carbapenemase and the PemK/Peml TA system, was used to study the intrinsic role of this TA system in phage infection (Table 2). Capsular type of each strain was determined using the Kaptive website (https://kaptiveweb.erc.monash.edu). In addition, the reference strain $K$. pneumoniae subsp. pneumoniae (ATCC ${ }^{8} 10031^{\mathrm{TM}}$ ) obtained from the American Culture Collection was used in this study, as well as the

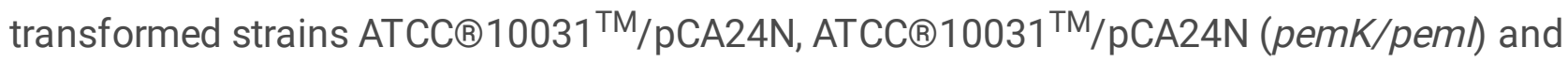


ATCC $\circledast 10031^{\mathrm{TM}} / \mathrm{pCA} 24 \mathrm{~N}$ (pemK) (Table 2 ) to study the induced expression of the PemK/Peml type II TA system during phage infection. The strains of ATCC ${ }^{8} 10031^{\mathrm{TM}}$ were transformed with the $\mathrm{pCA} 24 \mathrm{~N}\left(\mathrm{Cm}^{\mathrm{R}}\right.$, Lacl $^{q}$ ) expression plasmid ${ }^{40}$, inducible by IPTG and constructed by our group, harboring the complete pemK/pem/TA system and the pemK toxin alone ${ }^{28}$. All the strains were grown in Luria-Bertani (LB) medium, in the case of the transformed strains the media was supplemented with chloramphenicol (30 $\mu \mathrm{g} / \mathrm{ml}$ ) (LB-CM) to maintain the plasmid. 
Table 2

Bacterial strains and plasmids used in this study.

\section{Strains or Main characteristics}

Source or plasmids

$\begin{array}{lll}\text { ATCC }{ }^{8} 10031^{\text {TM }} & \text { K. pneumoniae subsp. pneumoniae reference strain } & \text { ATCC }\end{array}$

ATCC ${ }^{\circ} 10031^{\mathrm{TM}}$ _ K. pneumoniae subsp. pneumoniae reference strain with expression PCA24N

plasmid pCA24N

This

study

ATCC $\circledast 10031^{\mathrm{TM}}-\quad$ K. pneumoniae subsp. pneumoniae reference strain with expression $\mathrm{pCA} 24 \mathrm{~N}$

plasmid pCA24N with the type II TA system pemK/pem/

This

study

$($ pemK/peml)

ATCC $\circledast 10031^{\text {TM }}$ pCA24N (pemK)

pCA24N

pCA24N

(pemK/peml)

pCA24N (pemK) Expression plasmid pCA24N with the TA system pemK

K. pneumoniae reference strain with expression plasmid pCA24N with the toxin pemK

Expression plasmid $\mathrm{cm}^{\mathrm{R}}$, Laclq

Expression plasmid pCA24N with the TA system pemK/pemI

ST405-0XA48 Clinical strain isolated from wound (Genbank accession no.

WRXJ00000000) harboring the carbapenemase OXA-48 and the TA

system pemK/peml

ST16-OXA48

Clinical strain isolated from Urine (Genbank accession no.

WRXF00000000) harboring the carbapenemase OXA-48 and the TA system pemK/peml

ST13-0XA48

Clinical strain isolated from rectal sample (Genbank accession no.

WRWZ00000000) harboring the carbapenemase OXA-48 and the

TA system pemK/pem/

ST15-OXA48

Clinical strain isolated from axillary smear (Genbank accession no.

WRWX00000000) harboring the carbapenemase OXA-48 and the

TA system pemK/pem/

ST11-OXA48

Clinical strain isolated from urine (Genbank accession no.

WRWW00000000) harboring the carbapenemase OXA-48 and the

TA system pemK/pem/

ST974-OXA48

Clinical strain isolated from urine (Genbank accession no.

WRWT00000000) harboring the carbapenemase OXA-48 and the

TA system pemK/peml

ST15-OXA48 ${ }^{\mathrm{b}} \quad$ Clinical strain isolated from blood harboring the carbapenemase

OXA-48 and the TA system pemK/peml

This

study

ST15-0XA48 ${ }^{C} \quad$ Clinical strain isolated from blood harboring the carpabemase OXA-

48 and the TA system pemK/peml
28

28

1

This

study

40

1

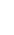

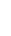


Ten lytic phages isolated from environmental water samples were used in this study. Briefly, $50 \mathrm{~mL}$ of water were taken near sewage plants and kept at room temperature until processing in the laboratory. Once in the laboratory, the samples were vortexed and centrifuged $4000 \times \mathrm{g} 10 \mathrm{~min}$. The supernatant was recovered and filtered through with $0.45 \mu \mathrm{m}$ and $0.22 \mu \mathrm{m}$ filters, to remove the cells and debris. Then, 1 $\mathrm{mL}$ of the filtered samples was added to $500 \mu \mathrm{L}$ of $K$. pneumoniae ATCC ${ }^{\circledR} 10031^{\mathrm{TM}}$ in $4 \mathrm{~mL}$ soft agar (0.5 $\% \mathrm{NaCl}, 1 \%$ tryptone and $0.4 \%$ agar; supplemented with $1 \mathrm{mM} \mathrm{CaCl} 2$ ) and poured onto TA agar plates $\left(0.5 \% \mathrm{NaCl}, 1 \%\right.$ tryptone and $1.5 \%$ agar; supplemented with $\left.1 \mathrm{mM} \mathrm{CaCl}_{2}\right)$; i.e., the double-layer method. Plates were incubated at $37^{\circ} \mathrm{C}$. Isolated plaques of different morphology (i.e., plaque size and presence of a surrounding halo) were then recovered by picking with a micropipette and stored at $-70^{\circ} \mathrm{C}$. In order to check the isolated plaques and purify them, two additional plaque assays and plaque picking steps were performed.

\section{Propagation of phage and transmission electron microscopy}

Plaque-purified phages were amplified in LB liquid media supplemented with $1 \mathrm{mM} \mathrm{CaCl} 2\left(\mathrm{LB}^{-\mathrm{CaCl}_{2}}\right)$ with shaking $(180 \mathrm{rpm})$ at $37^{\circ} \mathrm{C}$ by infecting an early logarithmic growth phase culture of ATCC $\AA 10031^{\mathrm{TM}}$ $\left(\mathrm{OD}_{600 \mathrm{~nm}}=0.3-0.4\right)$. After lysis, i.e. when the culture appear clear, bacteria and debris were removed by centrifugation $(2300 \times \mathrm{g} 10 \mathrm{~min})$ and filtration through $0.45 \mu \mathrm{m}$. Finally, the supernatants were tittered by the double-layer method by serial dilutions in SM buffer $\left(0.1 \mathrm{M} \mathrm{NaCl}, 10 \mathrm{mM} \mathrm{MgSO}{ }_{4}, 20 \mathrm{mM}\right.$ Tris-HCL pH 7.5) and stored at $4{ }^{\circ} \mathrm{C}$. Part of each high titer phages was processed by negatively stained with $1 \%$ aqueous uranyl acetate and then, analyzed by transmission electron microscopy on a JEOL JEM-1011 electron microscope.

\section{Phage DNA extraction and whole genome sequencing (WGS)}

Genomic phage DNA was isolated from the strains with the phenol:chloroform method following the phagehunting protocol

(https://phagesdb.org/media/workflow/protocols/pdfs/PCI_SDS_DNA_Extraction_2.2013.pdf). DNA concentrations and quality were measured using Nanodrop ND-10000 spectrophotometer (NanoDrop Technologies, Waltham, MA, USA) and Qubit fluorometer (Thermo Fisher Scientific, USA). Next, genomic libraries were prepared using the Nextera XT Library prep kit (Illumina), following the manufacter's instructions and the distribution of fragments lengths was checked in the Agilent 2100 Bioanalyser, using the Agilent Hight sensitivity DNA kit. Libraries were purified using the Mag-Bind RXNPure plus magnetic beads (Omega Biotek) and finally, the pool was sequenced in Miseq platform (Illumina Inc, USA). The quality of the FASTQ files was checked using the software FastQ $C^{41}$ and summarized using MultiQC ${ }^{42}$. Sequences of 300 bp paired-end reads of each isolate were assembled "de novo" with Spades V.3.15.243. All assembly were annotated using Patric 3.6.9 (http://www.patricbrc.org), Blastx (http://blast.ncbi.nlm.nih.gov), HHmer (http://hmmer.org) and HHpred (https://toolkit.tuebingen.mpg.de/tools/hhpred). The determination of the family and genus of the 
different phages was performed by sequence homology with the phage sequences available in the NCBI database. Complete genome sequences were included in GenBank BioProject PRJNA739095 (http://www.ncbi.nlm.nih.giv/bioproject/739095).

\section{Phage infectivity assay in solid medium}

Phage infectivity assay in solid medium was carried out by the spot test technique ${ }^{44}$, in the collection of clinical strain of K. pneumoniae. Briefly, $200 \mu \mathrm{L}$ of an overnight culture was mixed with $4 \mathrm{~mL}$ soft agar and poured onto TA agar plates. Once the soft medium had solidified, $15 \mu \mathrm{L}$ drops of high titer phages were added to the plates. For each strain, a negative control consisting of SM buffer was included for each plate. All the determinations were performed for triplicate. The criteria used to determine the phage infectivity was: - lack of spot, + presence of clear spot and +/- presence of turbid spot.

\section{Phage adsorption to bacterial host cells ST16-0XA48}

Adsorption of vB_KpnP-VAC1 and vB_KpnS-VAC7 phage to the bacterial surface receptors of clinical strain ST16-OXA48 was determined using the adsorption curve ${ }^{45}$. Briefly, an overnight of $K$. pneumoniae ST16-OXA48 was diluted $1: 100$ in $\mathrm{LB}^{-\mathrm{CaCl}_{2}}$, and incubated at $37^{\circ} \mathrm{C}$ at $180 \mathrm{rpm}$, until the culture reached $10^{8} \mathrm{CFU} / \mathrm{mL}$. At this point, the cultures were left at room temperature in the absence of agitation and infected with a phage suspension at an $\mathrm{MOI}$ of 0.001 . Every minute, $1 \mathrm{~mL}$ of culture was collected and placed in contact with $1 \%$ chloroform. Subsequently, the samples were centrifuged for 2 min at $12000 \times$ $\mathrm{g}$ in order to sediment cell debris and adsorbed phage. From the supernatant, serial dilutions were made in SM buffer, for subsequent plating on a double agar plate with the corresponding host plating strain. In the case of phage vB_KpnP-VAC1, the plating host was natural host of this phage, the reference strain ATCC $\circledast 10031^{\mathrm{TM}}$, because it was not able to produce a successful infection on the clinical strain ST16OXA48. However, in the case of vB_KpnS-VAC7 the plating host was the clinical strain ST16-OXA48. The number of phages mixed with bacterial host cells at time 0 was considered $100 \%$ free phages. The adsorption curve was performed for triplicate.

\section{One-step growth curve assay of VB_KpnS-VAC7 in the clinical strain ST16-0XA48}

The one-step growth curve of phage vB_KpnS-VAC7 was performed in the clinical strain ST16-OXA48, in order to determine the latent period and the burst size. The latent period was defined as the interval between adsorption of the phages to the bacterial cells and the release of phage progeny. Whereas, burst size of the phage was defined as number of viral particles released in each cycle of infection per bacterial cells. For this, an overnight of $K$. pneumoniae ST16-OXA48 was diluted 1:100 in $\mathrm{LB}-\mathrm{CaCl}_{2}$, and incubated at $37^{\circ} \mathrm{C}$ at $180 \mathrm{rpm}$, until the culture reached $10^{8} \mathrm{CFU} / \mathrm{mL}$. At this point, the culture was infected with a phage suspension at an $\mathrm{MOI}$ of 0.001 and left at room temperature for 4 minutes (adsorption time). Once the adsorption time had elapsed, the culture was washed by two successive $10 \mathrm{~min}$ centrifugations at $6000 \times \mathrm{g}$ in order to remove the free phages. After washing, the pellet was resuspended with LB-CaCl2; and $25 \mu \mathrm{l}$ of bacterial mixture was added to $25 \mathrm{~mL}$ of LB-CaCl2 (time 0 ) and incubated at $37^{\circ} \mathrm{C}$ under 
agitation. Then, $1 \mathrm{~mL}$ of culture was collected every $2 \mathrm{~min}$ for $18 \mathrm{~min}$, and serial dilutions were made in SM buffer and subsequently seeded on double agar plates for subsequent quantification. The one-step growth curve was performed for triplicate.

\section{RNA extraction of the selected clinical isolates.}

RNA extraction was performed using the High Pure RNA Isolation kit (Roche, Mannheim, Germany) from the samples taken from the infection curve of the clinical strain ST16-OXA48 after 15 min of phage infection at a $\mathrm{MOI}$ of 0.01 . The resulting extract was subsequently quantified in a NanoDrop ND-10000 spectrophotometer (NanoDrop Technologies, Waltham, MA, USA). The concentration was adjusted to 50 $\mathrm{ng} / \mu \mathrm{L}$ to yield efficiencies of $90-110 \%{ }^{46}$. All experiments were carried out in triplicate.

\section{Measurement of relative expression of the TA system by qRT-PCR}

The determination of the relative expression of the toxin (pemK) and the antitoxin (peml) after 15 min of phages infection at a MOI of 0.1 in the clinical strain ST16-OXA48, was carried out by qRT-PCR with a Lightcycler 480 RNA MasterHydrolisis Probe (Roche, Mannheim, Germany), under the following conditions: reverse transcription at $63^{\circ} \mathrm{C}$ for $3 \mathrm{~min}$, denaturation at $95^{\circ} \mathrm{C}$ for 30 seg, followed by 45 cycles of 15 seg at $95^{\circ} \mathrm{C}$ and $45 \mathrm{seg}$ at $60^{\circ} \mathrm{C}$ and, finally, cooling at $40^{\circ} \mathrm{C}$ for $30 \mathrm{seg}$. The UPL primers and probes used in the analysis are shown in Table 3. For statistical analysis of the data from these qRTPCR experiments, a 1.5-fold cut-off value was applied to identify differentially expressed TA genes according to other work ${ }^{47}$. Thus, TA gene expression was considered significantly up or downregulated if p-value $<0.05$ and fold change $>1.5$ or $<1.5$, respectively.

Table 3

Primers and probes used in this study.

\begin{tabular}{|c|c|c|c|}
\hline Primer Name & Sequences & Probes & References \\
\hline \multicolumn{4}{|c|}{ Peml (Antitoxin) } \\
\hline peml_Fow & CAGACGCCCGCAGTATTC & $102 /$ & This study \\
\hline peml_Rev & GCCGAGATTTCAGCGTTC & $102 /$ & This study \\
\hline \multicolumn{4}{|l|}{ PemK (Toxin) } \\
\hline pemK_Fow & CCGGACGATCGATATGAAAG & $142 /$ & This study \\
\hline pemK_Rev & GTCAGGATGGTGGCCAGA & $142 /$ & This study \\
\hline \multicolumn{4}{|c|}{ RecA (Housekeeping gene) } \\
\hline recA_Fow & GCCGAATTCCAGATCCTCTA & $148 /$ & This study \\
\hline recA_Rev & TCTTTCACGCCGAGGTCTAC & $148 /$ & This study \\
\hline
\end{tabular}


All of the experiments were carried out in a final volume of $20 \mu \mathrm{L}$ per well $(18 \mu \mathrm{L}$ of master mix and $2 \mu \mathrm{L}$ of RNA). Each experiment was performed for triplicate. For each strain, the expression of all genes, was normalized relative to the housekeeping gene, recA. Analysis of the control without reverse transcriptase confirmed the absence of DNA contamination.

\section{Infection curve and overexpression of TA system}

Infection curves were performed from the transformed strains of $K$. pneumoniae to study the effect of the induced expression of TA system in phage infection. For that, an overnight culture of the strains was diluted $1: 100$ in $\mathrm{LB}-\mathrm{CM}-\mathrm{CaCl}_{2}$, and incubated at $37^{\circ} \mathrm{C}$ at $180 \mathrm{rpm}$, until the culture reached an early logarithmic phase. At this point, the culture was induced by $1 \mathrm{mM}$ of IPTG, and infected with phages at an $\mathrm{MOI}$ of 0.1 . The optical density was measured every hour for $6 \mathrm{~h}$, and the number of $\mathrm{PFU} / \mathrm{mL}$ was determinate at 1, 3 and $6 \mathrm{~h}$ after infection by the double-layer method. The control was the strains without phages infection. All curves were performed for triplicate. For the statistical analysis, the Student's $t$-test with a significance of $95 \%$ was used with the Graphpad (Prism 8) software.

\section{Enzymatic assay using the Cell proliferation Reagent WST-1.}

The metabolic activity of the transformed strains ATCC $\AA 10031^{\mathrm{TM}}-\mathrm{pCA} 24 \mathrm{~N}, \mathrm{ATCC} \otimes 10031^{\mathrm{TM}}-\mathrm{pCA} 24 \mathrm{~N}$ (pemK/peml) and ATCC ${ }^{8} 10031^{\mathrm{TM}}$-pCA24N $($ pemK) after $2 \mathrm{~h}$ of infection with the phage VB_KpnP-VAC1 was analysed using a colorimetric enzymatic assay based on the water soluble tetrazolium salt (WST-1) reagent and electron mediators (Roche, Mannheim, Germany). Tetrazolium salts have become some of the widely used tools in cell biology for measuring the metabolic activity of cells ranging from mammalian to microbial origin ${ }^{48,49}$. Briefly, the cultures of the transformed strains were incubated at $37^{\circ} \mathrm{C}$ at $180 \mathrm{rpm}$, until the culture reached an early logarithmic phase. At this point, the culture was induced by $1 \mathrm{mM}$ of IPTG and infected with the phage vB_KpnP-VAC1 at an MOI of 0.1 . After $2 \mathrm{~h}$ of infection and two washing, the culture cells $\left(\mathrm{OD}_{600 \mathrm{~nm}}=0.1\right)$ were put in 96-well polystyrene plate (Corning Incorporated, NY, USA) and $10 \mu \mathrm{L} /$ well of the reagent was added. After $1 \mathrm{~h}$ of incubation at $37^{\circ} \mathrm{C}$ without shaking and $10 \mathrm{~min}$ with shaking $(180 \mathrm{rpm})$, the optical density was measured at $\mathrm{OD}_{480 \mathrm{~nm}}$. In all cases controls were the transformed strains without phage infection. The $\mathrm{OD}_{480 \mathrm{~nm}}$ of the medium culture (LB) in the presence of WST-1 reagent was used to normalize all data. All experiments were performed in triplicates. For the statistical analysis, the Student's $t$-test with a significance of $95 \%$ was used with the Graphpad (Prism 8) software.

\section{Declarations}

\section{ACKNOWLEDGEMENTS and FUNDING}

This study was funded by grants PI16/01163 and PI19/00878 awarded to M. Tomás within the State Plan for R+D+l 2013-2016 (National Plan for Scientific Research, Technological Development and Innovation 2008-2011) and co-financed by the ISCIII-Deputy General Directorate for Evaluation and Promotion of Research - European Regional Development Fund "A way of Making Europe" and Instituto 
de Salud Carlos III FEDER, Spanish Network for the Research in Infectious Diseases (REIPI, RD16/0016/0001, RD16/0016/0006 and RD16/CIII/0004/0002) and by the Study Group on Mechanisms of Action and Resistance to Antimicrobials, GEMARA (SEIMC, http://www.seimc.org/). M. Tomás was financially supported by the Miguel Servet Research Programme (SERGAS and ISCIII). I. Bleriot was financially supported by pFIS program (ISCIII, FI20/00302). O. Pacios and M. López was financially supported by a grant IN606A-2020/035 and IN606B-2018/008, respectively (GAIN, Xunta de Galicia) and M. Gonzalez-Bardanca was financially supported by the Rio Hortega program (ISCIII, CM20/00198).

\section{AUTHOR CONTRIBUTIONS}

I.B., L.B., O.P., L.F-G., developed the experiments, analysis of results and wrote manuscript. A.A., M.L., C.O.C., F.F-C, J.O., A.P., L.M-M., P.D-C., T.K.W., revised manuscript. M.T., financed and directed the experiments as well as supervised the writing of the manuscript.

\section{TRANSPARENCY DECLARATIONS}

The authors have not actions to declare

\section{References}

1. Bleriot, I. et al. Genomic analysis of 40 prophages located in the genomes of 16 carbapenemaseproducing clinical strains of Klebsiella pneumoniae. Microb Genom, 6, https://doi.org/10.1099/mgen.0.000369 (2020).

2. Bergh, O., Børsheim, K. Y., Bratbak, G. \& Heldal, M. High abundance of viruses found in aquatic environments. Nature, 340, 467-468 https://doi.org/10.1038/340467a0 (1989).

3. Lawrence, D., Baldridge, M. T. \& Handley, S. A. Phages and Human Health: More Than Idle Hitchhikers. Viruses, 11, https://doi.org/10.3390/v11070587 (2019).

4. Stanley, S. Y. \& Maxwell, K. L. Phage-Encoded Anti-CRISPR Defenses. Annu Rev Genet, 52, 445-464 https://doi.org/10.1146/annurev-genet-120417-031321 (2018).

5. Fineran, P. C. et al. The phage abortive infection system, ToxIN, functions as a protein-RNA toxinantitoxin pair. Proc Natl Acad Sci U S A, 106, 894-899 https://doi.org/10.1073/pnas.0808832106 (2009).

6. Song, S. \& Wood, T. K. Toxin/Antitoxin System Paradigms: Toxins Bound to Antitoxins Are Not Likely Activated by Preferential Antitoxin Degradation. Adv Biosyst, 4, e1900290 https://doi.org/10.1002/adbi.201900290 (2020).

7. Yang, Q. E. \& Walsh, T. R. Toxin-antitoxin systems and their role in disseminating and maintaining antimicrobial resistance. FEMS Microbiol Rev, 41, 343-353 https://doi.org/10.1093/femsre/fux006 (2017).

8. Song, S. \& Wood, T. K. A Primary Physiological Role of Toxin/Antitoxin Systems Is Phage Inhibition. Front Microbiol, 11, 1895 https://doi.org/10.3389/fmicb.2020.01895 (2020). 
9. Chan, W. T., Espinosa, M. \& Yeo, C. C. Keeping the Wolves at Bay: Antitoxins of Prokaryotic Type II Toxin-Antitoxin Systems. Front Mol Biosci, 3, 9 https://doi.org/10.3389/fmolb.2016.00009 (2016).

10. Sberro, H. et al. Discovery of functional toxin/antitoxin systems in bacteria by shotgun cloning. $\mathrm{Mol}$ Cell, 50, 136-148 https://doi.org/10.1016/j.molcel.2013.02.002 (2013).

11. LeRoux, M., Culviner, P. H., Liu, Y. J., Littlehale, M. L. \& Laub, M. T. Stress Can Induce Transcription of Toxin-Antitoxin Systems without Activating Toxin. Mol Cell, 79, 280-292288 https://doi.org/10.1016/j.molcel.2020.05.028 (2020).

12. Yamaguchi, Y., Park, J. H. \& Inouye, M. Toxin-antitoxin systems in bacteria and archaea. Annu Rev Genet, 45, 61-79 https://doi.org/10.1146/annurev-genet-110410-132412 (2011).

13. Ogura, T. \& Hiraga, S. Mini-F plasmid genes that couple host cell division to plasmid proliferation. Proc Natl Acad Sci U S A, 80, 4784-4788 (1983).

14. Gerdes, K., Rasmussen, P. B. \& Molin, S. Unique type of plasmid maintenance function: postsegregational killing of plasmid-free cells. Proc Natl Acad Sci U S A, 83, 3116-3120 (1986).

15. Fernández-García, L. et al. Toxin-Antitoxin Systems in Clinical Pathogens. Toxins (Basel), 8 , https://doi.org/10.3390/toxins8070227 (2016).

16. Moyed, H. S. \& Bertrand, K. P. hipA, a newly recognized gene of Escherichia coli K-12 that affects frequency of persistence after inhibition of murein synthesis. J Bacteriol, 155, 768-775 (1983).

17. Korch, S. B., Henderson, T. A. \& Hill, T. M. Characterization of the hipA7 allele of Escherichia coli and evidence that high persistence is governed by (p)ppGpp synthesis. Mol Microbiol, 50, 1199-1213 https://doi.org/10.1046/j.1365-2958.2003.03779.x (2003).

18. Schumacher, M. A. et al. Molecular mechanisms of HipA-mediated multidrug tolerance and its neutralization by HipB., 323, 396-401 https://doi.org/10.1126/science.1163806 (2009).

19. Page, R. \& Peti, W. Toxin-antitoxin systems in bacterial growth arrest and persistence. Nat Chem Biol, 12, 208-214 https://doi.org/10.1038/nchembio.2044 (2016).

20. Ren, D., Bedzyk, L. A., Thomas, S. M., Ye, R. W. \& Wood, T. K. Gene expression in Escherichia coli biofilms. App/ Microbiol Biotechnol, 64, 515-524 https://doi.org/10.1007/s00253-003-1517-y (2004).

21. Kim, Y., Wang, X., Ma, Q., Zhang, X. S. \& Wood, T. K. Toxin-antitoxin systems in Escherichia coli influence biofilm formation through YjgK (TabA) and fimbriae. J Bacteriol, 191, 1258-1267 https://doi.org/10.1128/JB.01465-08 (2009).

22. Wang, X. \& Wood, T. K. Toxin-antitoxin systems influence biofilm and persister cell formation and the general stress response. App/ Environ Microbiol, 77, 5577-5583 https://doi.org/10.1128/aem.0506811 (2011).

23. Pecota, D. C. \& Wood, T. K. Exclusion of T4 phage by the hok/sok killer locus from plasmid R1. J Bacteriol, 178, 2044-2050 (1996).

24. Koga, M., Otsuka, Y., Lemire, S. \& Yonesaki, T. Escherichia coli rnlA and rnlB compose a novel toxinantitoxin system., 187, 123-130 https://doi.org/10.1534/genetics.110.121798 (2011). 
25. Hazan, R. \& Engelberg-Kulka, H. Escherichia coli mazEF-mediated cell death as a defense mechanism that inhibits the spread of phage P1. Mol Genet Genomics, 272, 227-234 https://doi.org/10.1007/s00438-004-1048-y (2004).

26. Dy, R. L., Przybilski, R., Semeijn, K., Salmond, G. P. \& Fineran, P. C. A widespread bacteriophage abortive infection system functions through a Type IV toxin-antitoxin mechanism. Nucleic Acids Res, 42, 4590-4605 https://doi.org/10.1093/nar/gkt1419 (2014).

27. Wei, Y., Gao, Z., Zhang, H. \& Dong, Y. Structural characterizations of phage antitoxin Dmd and its interactions with bacterial toxin RnIA. Biochem Biophys Res Commun, 472, 592-597 https://doi.org/10.1016/j.bbrc.2016.03.025 (2016).

28. Bleriot, I. et al. Mechanisms of Tolerance and Resistance to Chlorhexidine in Clinical Strains of Klebsiella pneumoniae Producers of Carbapenemase: Role of New Type II Toxin-Antitoxin System, PemIK. Toxins (Basel), 12, https://doi.org/10.3390/toxins12090566 (2020).

29. Adriaenssens, E. \& Brister, J. R. How to Name and Classify Your Phage: An Informal Guide. Viruses, 9 , https://doi.org/10.3390/v9040070 (2017).

30. Domingo-Calap, P., Beamud, B., Mora-Quilis, L., González-Candelas, F. \& Sanjuán, R. Isolation and Characterization of Two Klebsiella pneumoniae Phages Encoding Divergent Depolymerases. Int $J$ Mol Sci, 21, https://doi.org/10.3390/ijms21093160 (2020).

31. de Jonge, P. A., Nobrega, F. L., Brouns, S. J. J. \& Dutilh, B. E. Molecular and Evolutionary Determinants of Bacteriophage Host Range. Trends Microbiol, 27, 51-63 https://doi.org/10.1016/j.tim.2018.08.006 (2019).

32. Wicke, L. et al. Introducing differential RNA-seq mapping to track the early infection phase for Pseudomonas phage $\triangle \mathrm{KZ}$. RNA Biol, 1-12 https://doi.org/10.1080/15476286.2020.1827785 (2020).

33. Harms, A., Brodersen, D. E., Mitarai, N. \& Gerdes, K. Toxins, Targets, and Triggers: An Overview of Toxin-Antitoxin Biology. Mol Cell, 70, 768-784 https://doi.org/10.1016/j.molcel.2018.01.003 (2018).

34. Hyman, P. \& Abedon, S. T. Bacteriophage host range and bacterial resistance. Adv Appl Microbiol, 70, 217-248 https://doi.org/10.1016/S0065-2164(10)70007-1 (2010).

35. Fraikin, N., Goormaghtigh, F. \& Van Melderen, L. Type II Toxin-Antitoxin Systems: Evolution and Revolutions. J Bacteriol, 202, https://doi.org/10.1128/jb.00763-19 (2020).

36. Moreno-Del Álamo, M., Marchisone, C. \& Alonso, J. C. Antitoxin $\varepsilon$ Reverses Toxin Z-Facilitated Ampicillin Dormants. Toxins (Basel), 12, https://doi.org/10.3390/toxins12120801 (2020).

37. Agarwal, S. \& Bhatnagar, R. Identification and characterization of a novel toxin-antitoxin module from Bacillus anthracis. FEBS Lett, 581, 1727-1734 https://doi.org/10.1016/j.febslet.2007.03.051 (2007).

38. Zhang, J., Zhang, Y., Zhu, L., Suzuki, M. \& Inouye, M. Interference of mRNA function by sequencespecific endoribonuclease PemK. J Biol Chem, 279, 20678-20684 https://doi.org/10.1074/jbc.M314284200 (2004).

39. Yamaguchi, Y. \& Inouye, M. Regulation of growth and death in Escherichia coli by toxin-antitoxin systems. Nat Rev Microbiol, 9, 779-790 https://doi.org/10.1038/nrmicro2651 (2011). 
40. Kitagawa, M. et al. Complete set of ORF clones of Escherichia coli ASKA library (a complete set of E. coli K-12 ORF archive): unique resources for biological research. DNA Res, 12, 291-299 https://doi.org/10.1093/dnares/dsi012 (2005).

41. Wingett, S. W., Andrews, S. \& FastQ Screen A tool for multi-genome mapping and quality control. F1000Res, 7, 1338 https://doi.org/10.12688/f1000research.15931.2 (2018).

42. Ewels, P., Magnusson, M., Lundin, S. \& Käller, M. MultiQC: summarize analysis results for multiple tools and samples in a single report., 32, 3047-3048 https://doi.org/10.1093/bioinformatics/btw354 (2016).

43. Bankevich, A. et al. SPAdes: a new genome assembly algorithm and its applications to single-cell sequencing. J Comput Biol, 19, 455-477 https://doi.org/10.1089/cmb.2012.0021 (2012).

44. Kutter, E. Phage host range and efficiency of plating. Methods Mol Biol, 501, 141-149 https://doi.org/10.1007/978-1-60327-164-6_14 (2009).

45. Kropinski, A. M. Measurement of the rate of attachment of bacteriophage to cells. Methods Mol Biol, 501, 151-155 https://doi.org/10.1007/978-1-60327-164-6_15 (2009).

46. Rumbo, C. et al. Contribution of efflux pumps, porins, and $\beta$-lactamases to multidrug resistance in clinical isolates of Acinetobacter baumannii. Antimicrob Agents Chemother, 57, 5247-5257 https://doi.org/10.1128/AAC.00730-13 (2013).

47. Van Acker, H., Sass, A., Dhondt, I., Nelis, H. J. \& Coenye, T. Involvement of toxin-antitoxin modules in Burkholderia cenocepacia biofilm persistence. Pathog Dis, 71, 326-335 https://doi.org/10.1111/2049-632X.12177 (2014).

48. Berridge, M. V., Herst, P. M. \& Tan, A. S. Tetrazolium dyes as tools in cell biology: new insights into their cellular reduction. Biotechnol Annu Rev, 11, 127-152 https://doi.org/10.1016/S13872656(05)11004-7 (2005).

49. Tsukatani, T. et al. Colorimetric cell proliferation assay for microorganisms in microtiter plate using water-soluble tetrazolium salts. J Microbiol Methods, 75, 109-116 https://doi.org/10.1016/j.mimet.2008.05.016 (2008).

\section{Figures}



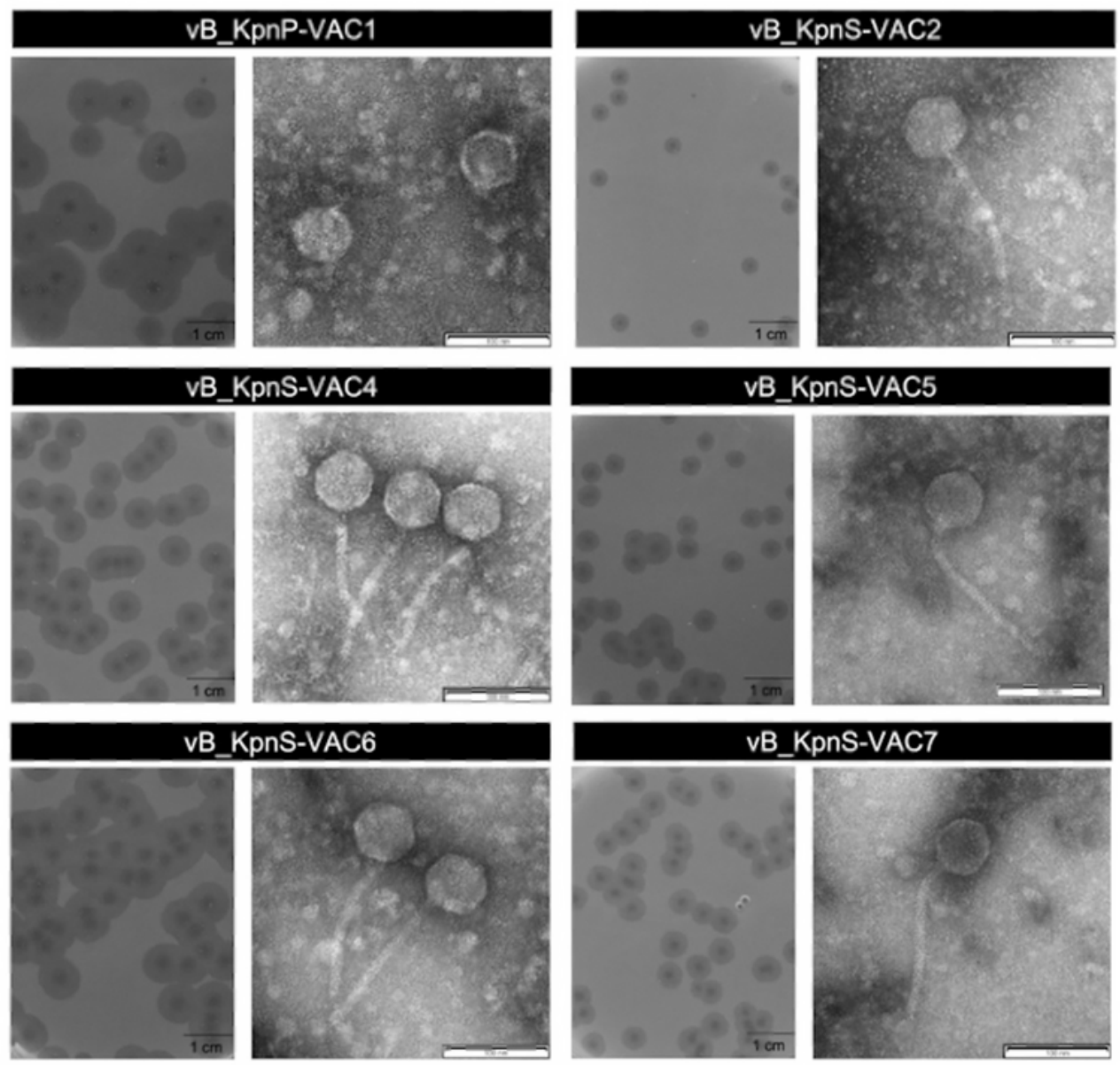

\section{vB_KpnS-VAC8}
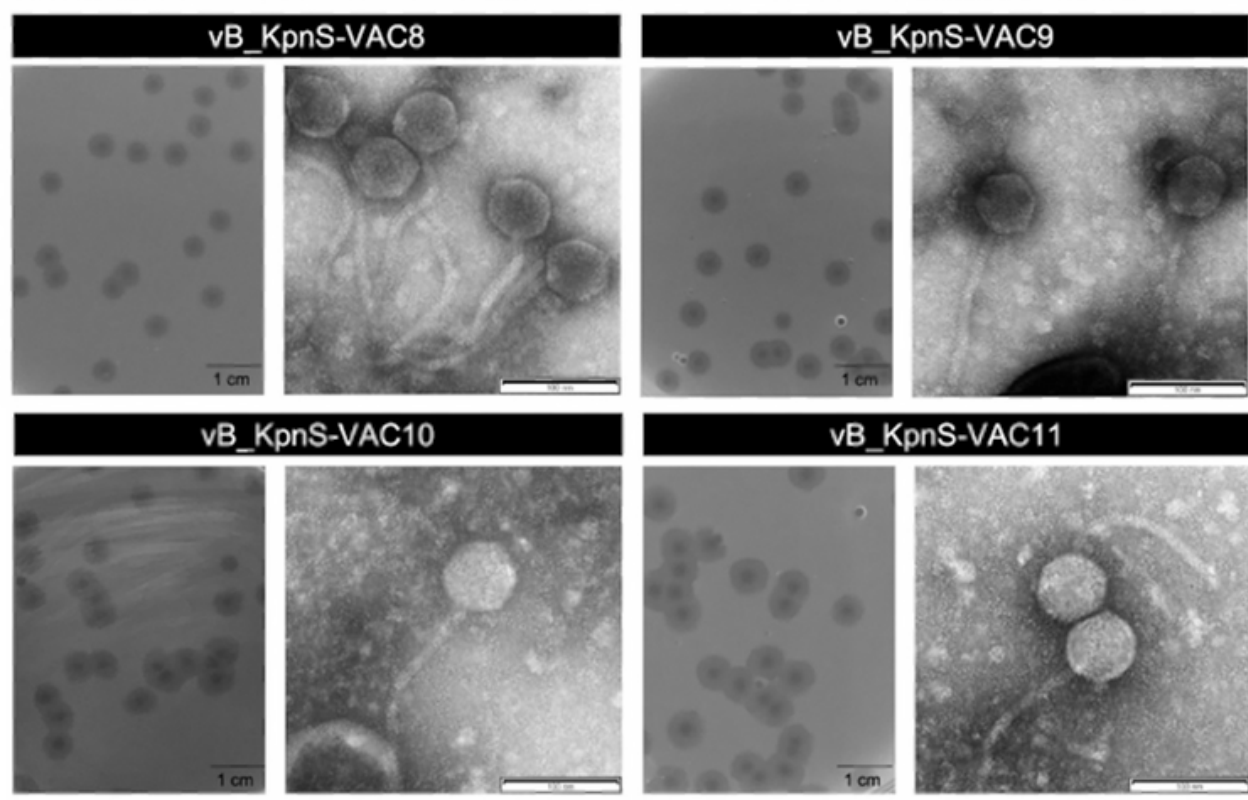

\section{KpnS-VAC10}
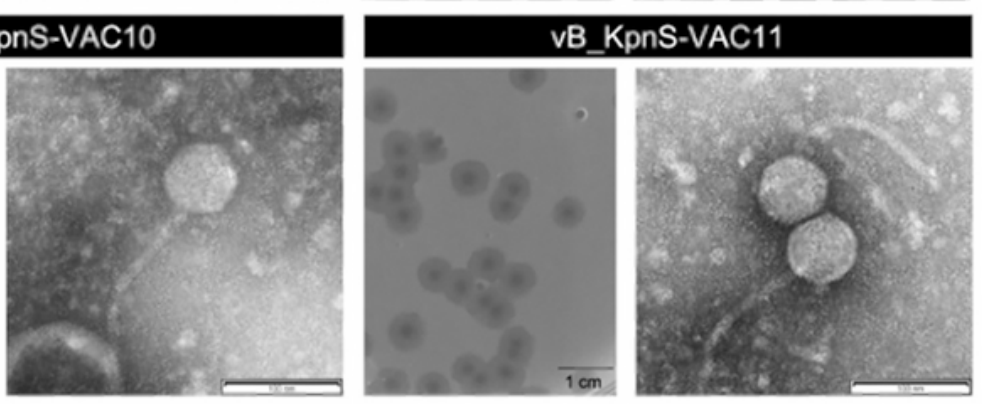

\section{Figure 1}

Plaque morphologies as well as transmission electron microscopy photographs showing the structure of the ten phages under study. All of them belong to the order Caudovirales, with vB_KpnP-VAC1 member of the Podoviridae family characterized by having a short tail while all the others are members of the Siphoviridae family characterized by having a large, flexible tails. The scall bar of the plaque morphologies represent $1 \mathrm{~cm}$ while the scall bar of the TEM represent $100 \mathrm{~nm}$. 
(A)

\begin{tabular}{|c|c|c|c|c|c|c|c|c|c|c|c|}
\hline \multicolumn{2}{|c|}{ Strains } & \multicolumn{10}{|c|}{ Phage vB_ } \\
\hline Name & Capsular type & KpnP-VAC1 & KpnS-VAC2 & KpnS-VAC4 & KpnS-VAC5 & KpnS-VAC6 & KpnS-VAC7 & KpnS-VAC8 & KpnS-VAC9 & KpnS-VAC10 & KpnS-VAC11 \\
\hline ST405-OXA48 & KL151 & $\cdot$ & - & - & - & - & - & $\cdot$ & - & - & - \\
\hline$\underline{\text { ST16-0XA48 }}$ & KL51 & - & + & + & + & + & + & + & + & + & + \\
\hline ST13-OXA48 & KL30 & - & - & + & $+/-$ & - & $+/-$ & $+/-$ & - & $+/-$ & - \\
\hline ST15-OXA48 & KL112 & - & - & $+1-$ & $+1-$ & - & - & - & - & - & - \\
\hline ST11-OXA48 & KL24 & - & - & $+/-$ & $+/-$ & - & $+/-$ & $+/-$ & $+1-$ & - & - \\
\hline ST974-OXA48 & KL38 & - & - & $+1-$ & $+1-$ & $+1-$ & - & + & + & + & + \\
\hline ST15-OXA48 & KL112 & - & - & + & + & - & + & - & - & - & - \\
\hline ST15-OXA48 ${ }^{C}$ & KL112 & - & - & - & - & - & - & - & - & - & - \\
\hline
\end{tabular}

(B)

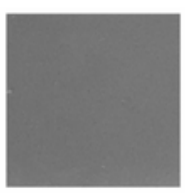

(C)

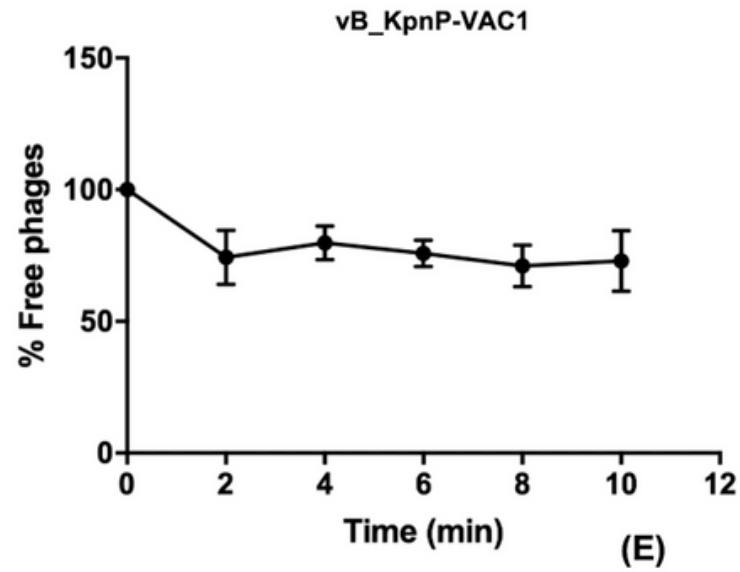

(D)

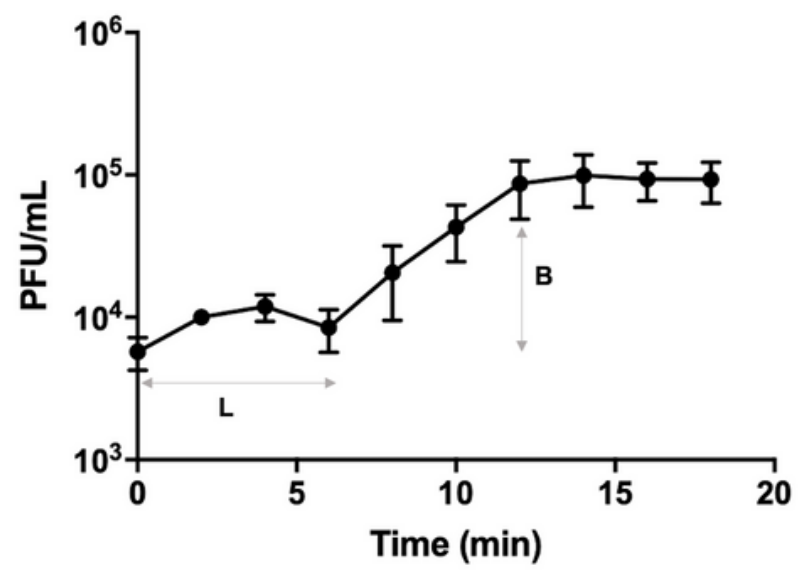

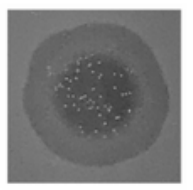
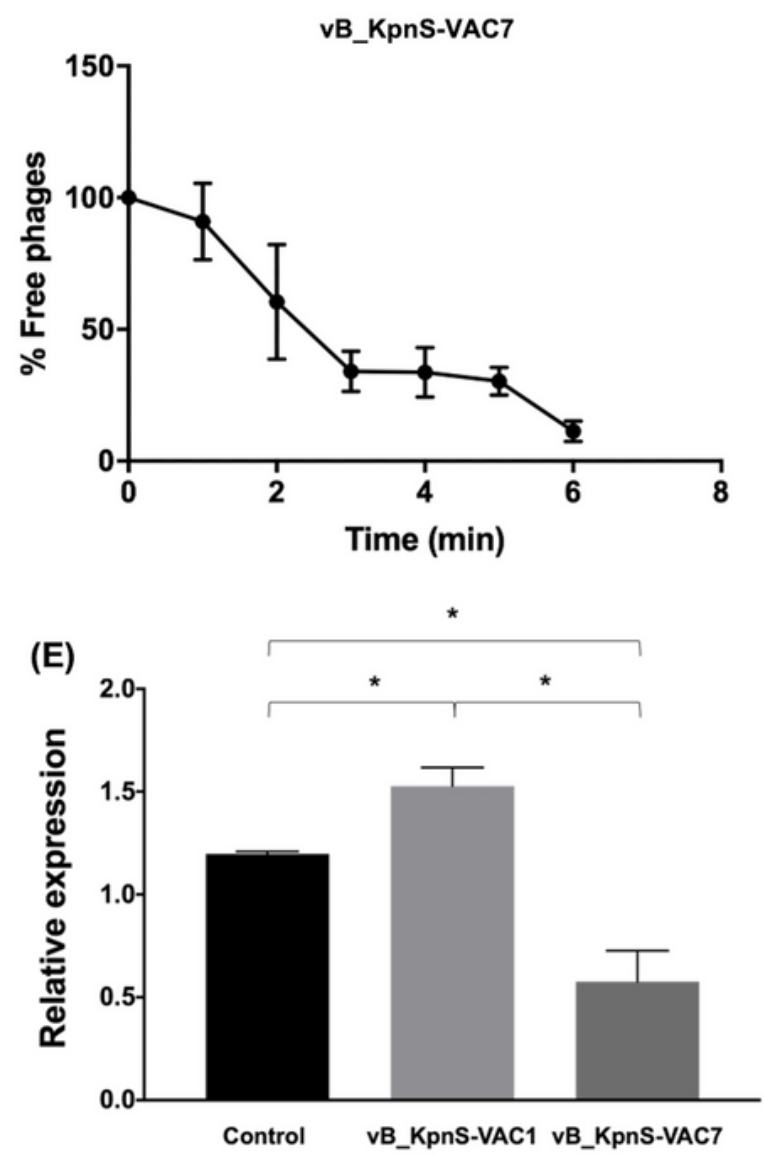

Figure 2

(A) The strain infectivity assay was performed with the ten lytic phages in the collection of clinical strains of K. pneumoniae, where all strains harbored the OXA-48 carbapenemase and the PemK/Peml TA system. -, Lack of spot; +, presence of clear spot; +/-, presence of turbid spot. (B) Spot test of phages vB_KpnPVAC1 and vB_KpnS-VAC7 in the clinical strain ST16-OXA48. (C) Adsorption curve of phages vB_KpnPVAC1 (right) and vB_KpnS-VAC7 (left) at an MOI of 0.001 in the clinical strain ST16-OXA48. The errors 
bars represent the standard deviation of the three experimental replicates. (D) One-step growth curve of phage vB_KpnS-VAC7 at an MOI of 0.001 in the clinical strain ST16-OXA48. L: latent time; B:Burst-size. The errors bar represents the standard deviation of the three experimental replicates. (E) Relative expression of pemK toxin with respect to peml antitoxin in the clinical strain ST16-OXA48 of K. pneumoniae after 15 min of infection with the phages VB_KpnP-VAC1, which not produce infection, and vB_KpnS-VAC7, which produce infection. ${ }^{*}, \mathrm{p}$-value $<0.05$. The errors bars represent the standard deviation of the three experimental replicates. The control was the strain without phage infection.
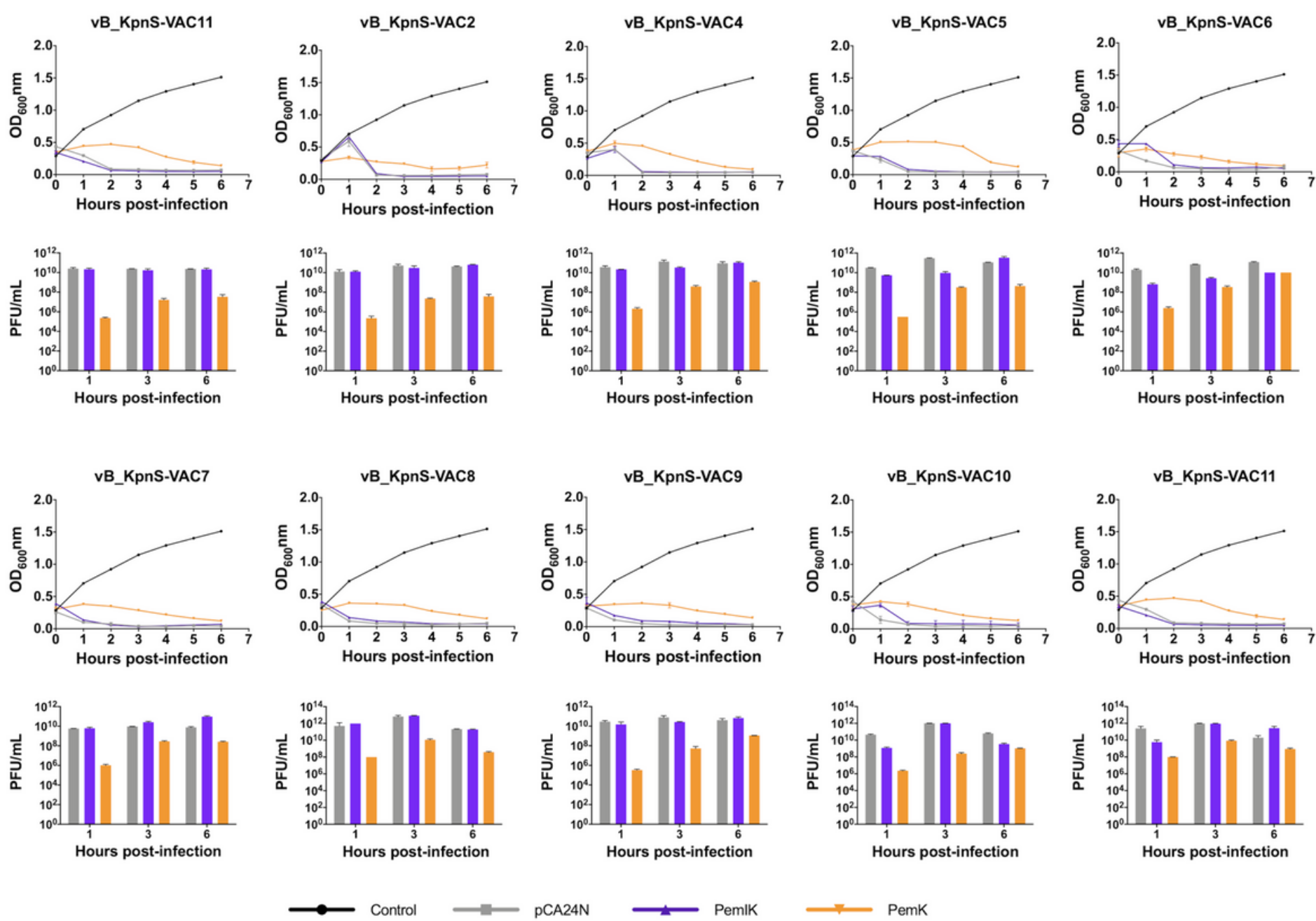

Figure 3

Infection curve of the strains ATCC $® 10031 \mathrm{TM} /$ pCA24N, ATCC $B 10031 \mathrm{TM} / \mathrm{pCA} 24 \mathrm{~N}$ (pemK/peml) and ATCC $\circledast 10031 \mathrm{TM} / \mathrm{pCA} 24 \mathrm{~N}$ (pemK) in presence of the ten lytic phages, as well as the enumeration of $\mathrm{PFU} / \mathrm{mL}$ after 1,3 and $6 \mathrm{~h}$ of infection. The strain ATCC $\AA 10031 \mathrm{TM} / \mathrm{pCA} 24 \mathrm{~N}$, harboring the emptyplasmid, without phage infection was used as a control in the infection curve. In all cases there is a significative difference ( $p$-value $<0.05$ ) between the enumeration of $P F U / m L$ of the strain ATCC $® 10031 T M / p C A 24 N$ (pemK) and the strains ATCC $® 10031 T M / p C A 24 N$ and ATCC®10031TM/pCA24N (pemK/peml). 


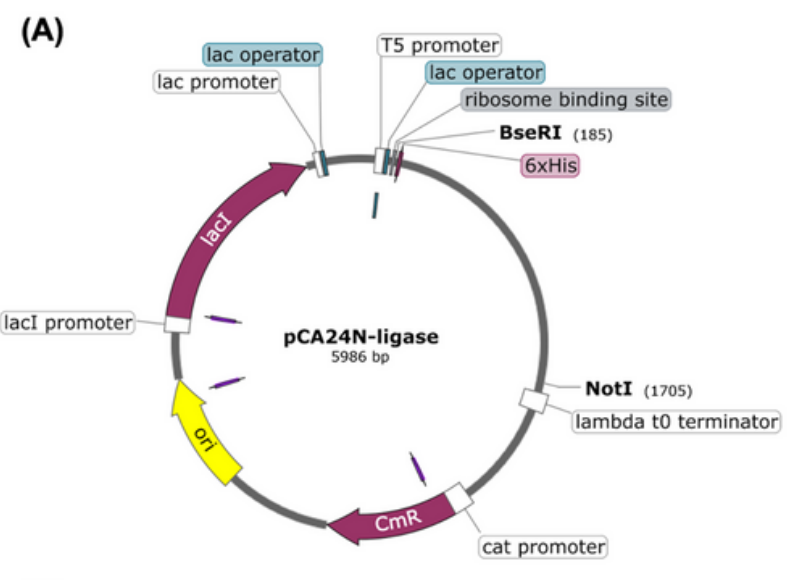

(C)

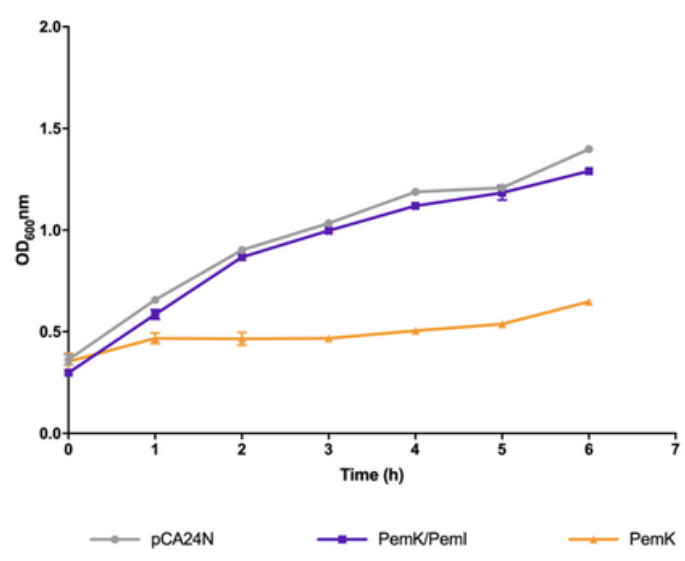

(B)

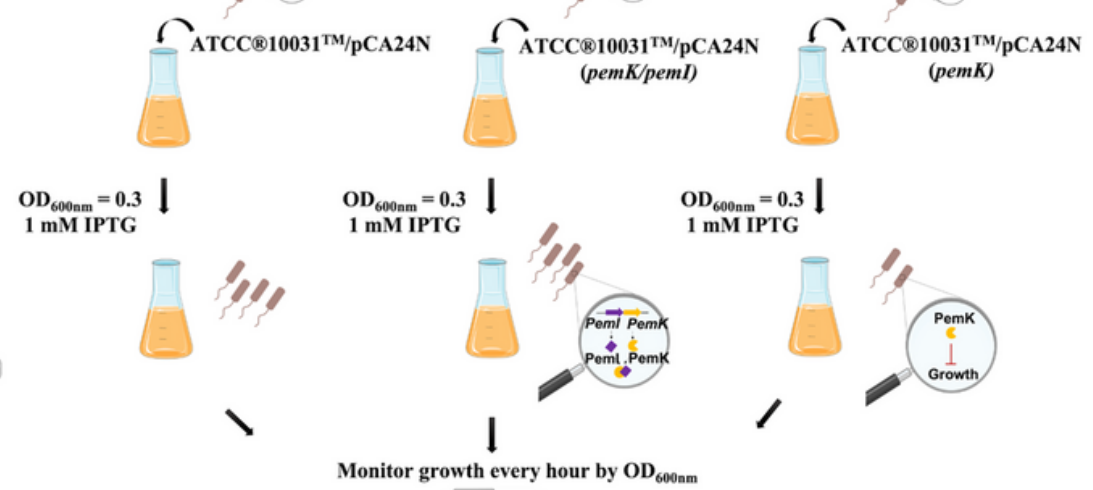

(D)

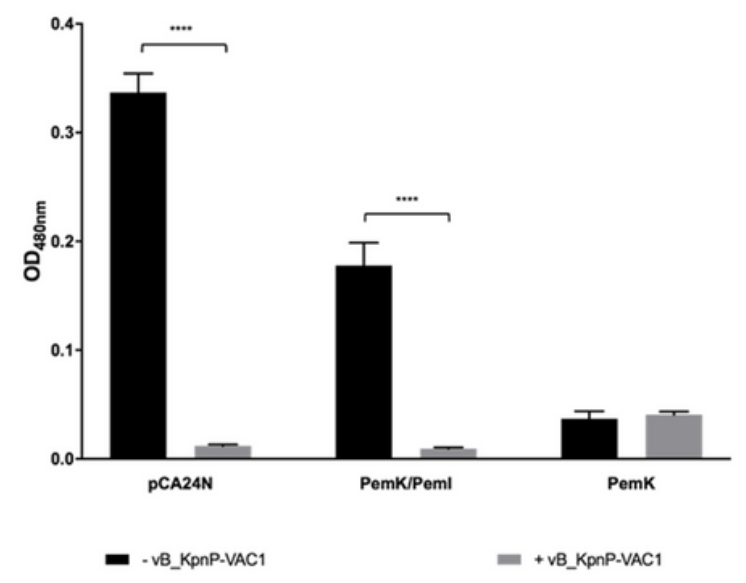

Figure 4

(A) Graphical representation of the pCA24N plasmid made with Snapgene software with the location of the restriction enzymes used in this work to perform the transformed strains ATCC $® 10031 T M / p C A 24 N$ (pemK/peml) and ATCC®10031TM/pCA24N (pemK). The graphical representation was performed using Snap Gene software. (B) Schematic overview of growth curves. (C) Growth curves of the strains ATCC®10031TM/pCA24N, ATCC®10031TM/pCA24N (pemK/peml) and ATCC®10031TM/pCA24N (pemK) in presence of $1 \mathrm{mM} \mathrm{IPTG}$ added at an early logarithmic phase. The strain ATCC ${ }^{8} 10031 T M / p C A 24 N$, harboring the empty-plasmid, was used as a control. The errors bars represent the standard deviation of the three experimental replicates. (D) Measurement of the metabolic activity by the colorimetric assay (WST-1 based) of the transformed strains ATCC $B 10031 \mathrm{TM} / \mathrm{pCA} 24 \mathrm{~N}$, ATCC ${ }^{8} 10031 T M / p C A 24 N$ (pemK/peml) and ATCC®10031TM/pCA24N (pemK) after $2 \mathrm{~h}$ of IPTG induction and with $\mathrm{VB} \_\mathrm{KpnP}-\mathrm{VAC1}$ infection at an $\mathrm{MOI}$ of 0.1 . The controls were the transformed strain without phage infection. ${ }^{* \star \star *}, \mathrm{p}$-value $<0.001$. The errors bars represent the standard deviation of the three experiment replicates. 